\title{
Multimodal radiological imaging of collagenous fibroma arising from the subacromial region in a patient with osteosarcoma: A case report
}

\author{
HIROAKI MURATA, KAN IMAI, KAZUYA NAKAGAWA and YASUNORI NISHIGAKI \\ Department of Orthopaedics, Matsushita Memorial Hospital, Moriguchi, Osaka 570-8540, Japan
}

Received February 6, 2018; Accepted December 7, 2018

DOI: $10.3892 /$ mco.2019.1798

\begin{abstract}
Collagenous fibroma arising from the subacromial region is extremely rare. It is important to distinguish collagenous fibroma from other fibrous tumors including desmoid tumors, to differentiate between the prognoses and management strategies, including surgical treatment. The present case report describes the case of a 42-year-old man with a collagenous fibroma of the subacromial region. He received a follow-up examination following treatment for osteosarcoma. Positron emission tomography (PET) scans used to assess for metastatic lesions indicated uptake in his left shoulder. The maximum standardized uptake value was 2.4. Magnetic resonance imaging demonstrated iso-intensity to muscle on T1-weighted images and iso-intensity with slightly high intensity on T2-weighted images. Post-contrast fat-suppressed magnetic resonance images indicated slightly heterogeneous enhancement of the lesion. There were no notable results from X-rays, bone scintigraphy and thallium-201 scintigraphy. Histological examination revealed collagenous fibroma. To the best of our knowledge, the present case is only the second incidence of collagenous fibroma arising from the subacromial region, and the first description of thallium-201 scintigraphy and PET scans in collagenous fibroma. The multimodal radiological data of this case may be useful for assisting in the differentiation of fibrous tumor types, including collagenous fibroma.
\end{abstract}

\footnotetext{
Correspondence to: Dr Hiroaki Murata, Department of Orthopaedics, Matsushita Memorial Hospital, 5-55 Sotojima-cho, Moriguchi, Osaka 570-8540, Japan

E-mail: murah@koto.kpu-m.ac.jp
}

Abbreviations: MRI, magnetic resonance imaging; PET, positron emission tomography; $\mathrm{SUV}_{\max }$, maximum standardized uptake value

Key words: collagenous fibroma, magnetic resonance imaging, positron emission tomography, thallium-201 scintigraphy, subacromial region

\section{Introduction}

Collagenous fibroma is a rare benign fibrous soft tissue tumor. This tumor was first described by Evans (1) as desmoplastic fibroblastoma, and subsequently renamed collagenous fibroma by Nielsen et al (2). It is a mass with slow growth located in subcutaneous tissue or skeletal muscle, and the most common sites are the upper extremities (1,3-5).

Diagnostic imaging data of collagenous fibroma have not been clearly described. Although magnetic resonance imaging (MRI) data for collagenous fibroma have been described in previous studies (3-12), the tumors did not exhibit a common pattern, and often produced similar results compared with fibrous tumors, including desmoid tumors $(13,14)$. It is important to achieve the correct diagnosis and offer management including surgical treatment for collagenous fibroma, as neither local recurrence nor metastasis following surgical resection have been identified.

The present case study describes an unusual case of collagenous fibroma arising from the subacromial region in a patient with osteosarcoma who was observed for follow-up of local recurrence and metastasis. Lesions of the subacromial region have rarely been described. To the best of our knowledge, this case was the second to occur in the subacromial region, following a case described by Milnes et al (8). In addition, multimodal radiological data using not only MRI but also thallium-201 scintigraphy, bone scintigraphy and positron emission tomography (PET) are presented, and the distinguishing features of collagenous fibroma from desmoid tumors are also discussed.

\section{Case report}

The patient was 42-year-old man with a 6-month history of dull pain in his left shoulder. He had no tenderness, no mass and no limitation in the range of motion in his shoulder. $\mathrm{He}$ had no history of trauma. Laboratory examination revealed that his white blood cell count was 5,500 $\mu \mathrm{l}$ (normal range, $4,000-9,000 / \mu \mathrm{l}), \mathrm{C}$-reactive protein levels were $0.13 \mathrm{mg} / \mathrm{dl}$ (normal range, $<0.25 \mathrm{mg} / \mathrm{dl}$ ) and alkaline phosphatase levels were $214 \mathrm{U} / 1$ (normal range, 1-340 U/1). Plasma electrolytes, liver and kidney function tests were within the normal ranges. His history described osteosarcoma in his right proximal humerus with pain in his right shoulder 3 years previously 
(Fig. 1A). He received chemotherapy and underwent wide tumor excision and endoprosthetic replacement (Fig. 1B). Although thallium-201 scintigraphy and bone scintigraphy had been performed to check postoperative recurrence and metastasis 1 year previously, these investigations indicated that there was no uptake in his left shoulder (Fig. 2). There was also no evidence of recurrence or metastasis. PET scans were conducted to assess for metastatic lesions, and demonstrated uptake in his left shoulder (Fig. 3). The maximum standardized uptake value $\left(\mathrm{SUV}_{\max }\right)$ was 2.4. MRI scans demonstrated a mass with clear margins, measuring $46 \times 22 \times 14 \mathrm{~mm}$ in size in the subacromial region. The margins between the mass and the supraspinatus or infraspinatus muscle were clear. The lesion was iso-intense to muscle on T1-weighted images (Fig. 4A) and iso-intense with a slightly high intensity area on T2-weighted images (Fig. 4B). Post-contrast fat-suppressed MRI scans indicated slightly heterogeneous enhancement of the lesion (Fig. 4C). There were no data from the X-ray scans performed.

An open biopsy was planned, although metastasis of osteosarcoma was not suspected from the clinical imaging data. During the procedure, the deltoid muscle was split, and a whitish mass was identified in the subacromial space. When a part of the mass was pinched, the white and elastic hard mass was easily excised, as it was not adhered to adjacent tissues (Fig. 5A). Macroscopically, it appeared as a white, elastic, hard and well-circumscribed mass (Fig. 5B). The resected tissue was fixed with $10 \%$ formalin for $24 \mathrm{~h}$ at room temperature. Paraffin embedding was performed as follows: $70 \%$ ethanol (4 h), 80\% and $90 \%$ ethanol ( $1 \mathrm{~h}$ each), $100 \%$ ethanol $(4 \mathrm{~h})$, xylene $(4 \mathrm{~h})$, and paraffin wax $\left(60^{\circ} \mathrm{C} ; 3 \mathrm{~h}\right)$. The paraffin embedded specimens $(2 \mu \mathrm{m})$ were examined via hematoxylin and eosin staining (at room temperature for $50 \mathrm{~min}$ ) and analyzed under an optical microscope (magnification, x40 and $\mathrm{x} 100)$. The tumor demonstrated fibrous and myxomatous matrix areas. Few vascular spaces were observed (Fig. 6A). Histological examination revealed a hypocellular tumor consisting of spindle- or stellate-shaped fibroblasts with oval nuclei in abundant collagen fiber and myxocollagenous areas. The tumor exhibited low vascularity. No mitosis or necrosis was observed (Fig. 6B). Histological results were consistent with a collagenous fibroma. Excision resulted in immediate pain relief. He has had no recurrence during the 4 years since the surgery.

\section{Discussion}

Collagenous fibroma is a rare benign fibrous soft tissue tumor with a slow growth rate and clear margins, located in subcutaneous and skeletal muscle. The tumor is more common in males aged 50-70 years old. Miettinen and Fetsch (3) suggested that these types of tumors range in size from $1-20 \mathrm{~cm}$ (median $3 \mathrm{~cm}$ ), and common locations include the arms (24\%), shoulders $(19 \%)$, posterior neck and upper back, in particular the scapular areas (14\%), feet and ankles (14\%), legs (14\%), hands (8\%), and abdominal wall and hip regions (6\%). Although the shoulder girdle is the second most common location (5-7), involvement of the subacromial region is rare. The present case report is the second case occurring in the subacromial region, following a case described by Milnes et al (8). The majority of

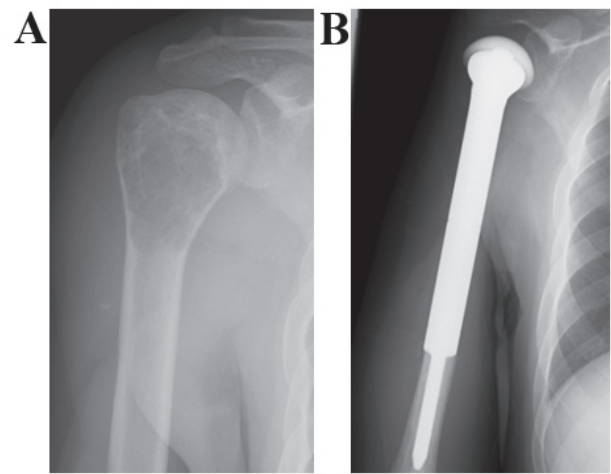

Figure 1. X-ray scans obtained 3 years previously. (A) An osteolytic lesion with unclear margins was observed in the patient's right proximal humerus. (B) Endoprosthetic replacement was performed.
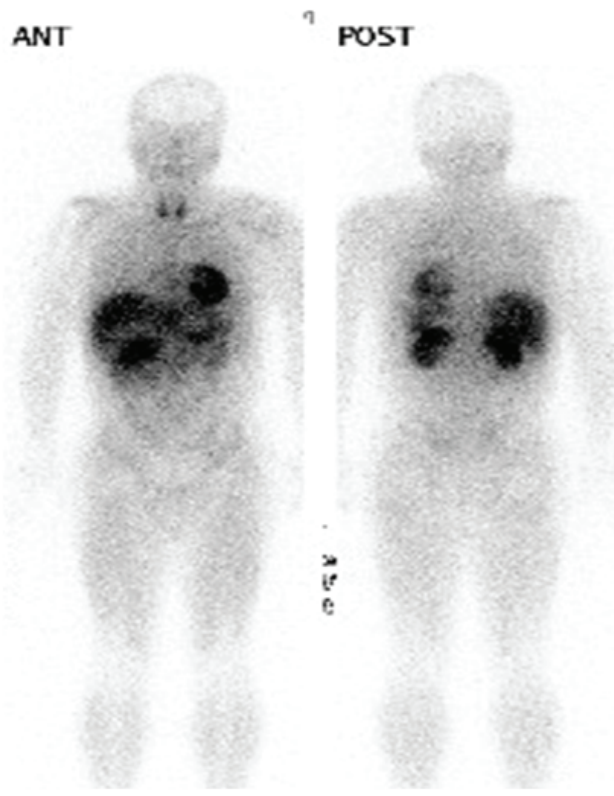

Figure 2. Thallium-201 scintigraphy from 1 year previously. There was no uptake in patient's left shoulder. ANT, anterior position; POST, posterior position.

previous studies described tumors as being painless (1,3-5,7). In the present case, the patient experienced dull pain in his shoulder. The cause was considered to be the location of the tumor, contributing to pain by compressing the subacromial space.

Histologically, collagenous fibroma is characterized by spindle- to stellate-shaped fibroblasts and myofibroblasts embedded in a prominent collagenous matrix (1). The cellularity is low, mitotic figures are rare or absent and tumor necrosis is usually not observed $(1,3,4,9-12)$. The differential diagnosis for collagenous fibroma includes fibroma of the tendon sheath, nodular fasciitis, neurofibroma, desmoid tumors and low-grade malignant tumors (1-3). In particular, it is important to distinguish collagenous fibroma from desmoid tumors, as the strategies for treatment and incidence of recurrence are different, despite similar imaging and cytological features of the two tumors $(1,12)$. Although the treatment for collagenous fibroma is local resection, with no demonstrated incidence of local recurrence or metastases, wide excision 

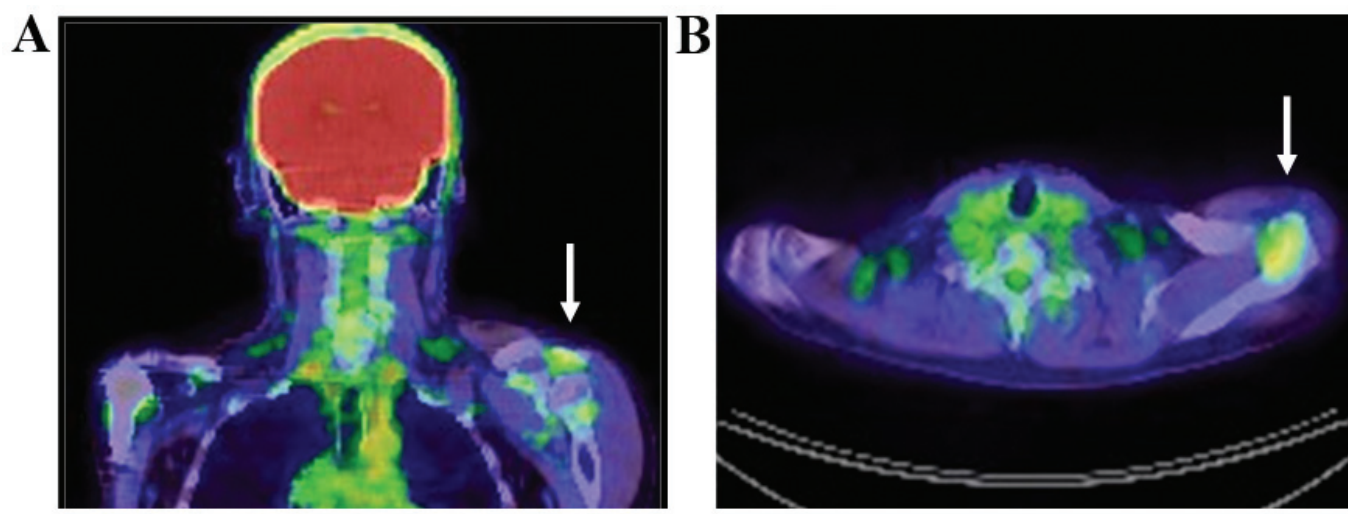

Figure 3. PET prior to surgery. (A) Coronal and (B) axial PET indicated uptake in the patient's left shoulder (arrows). Maximum standardized uptake value was 2.4. PET, positron emission tomography.
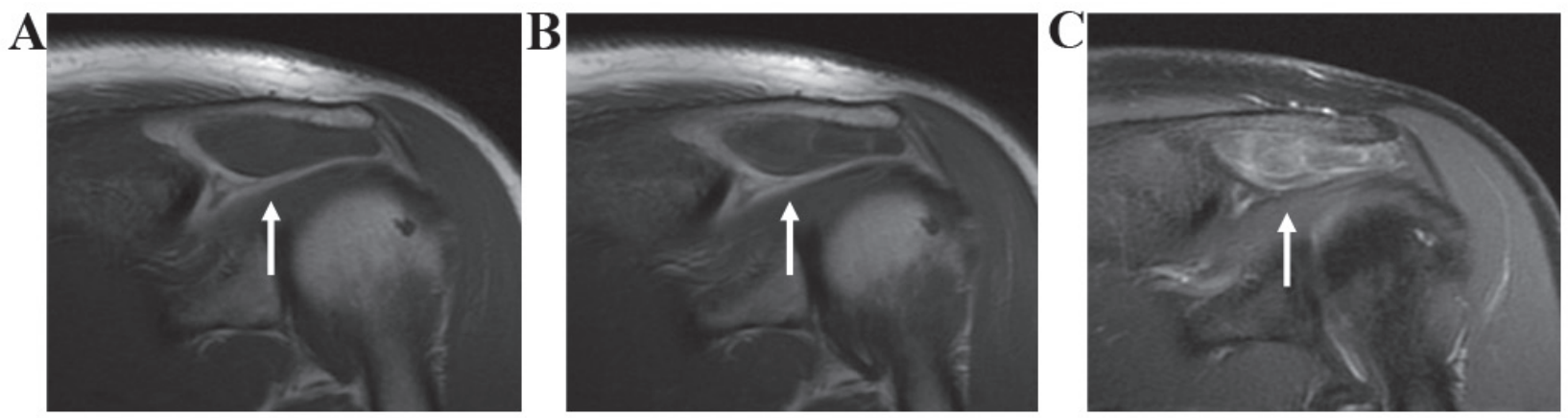

Figure 4. MRI prior to surgery. (A) Coronal T1-weighted images revealed a well-circumscribed, homogeneous mass (arrow) in the subacromial region with iso-intensity to muscle. (B) The lesion was iso-intense with a slightly high intensity area on the T2-weighted images. (C) Post-contrast fat-suppressed magnetic resonance images indicated slightly heterogeneous enhancement of the lesion. MRI, magnetic resonance imaging.

may be performed with wide margins including surrounding muscle to prevent local recurrence of desmoid tumors $(9,12)$. It is therefore important to accurately diagnose tumors as collagenous fibroma using preoperative diagnostic imaging, to prevent overtreatment that may result in a loss of function $(7,12)$. However, the radiological features of collagenous fibroma are not widely recognized as there are so few published studies.

MRI data for collagenous fibroma have been described previously (3-12). All the cases predominantly described iso-intensity to muscle, including several areas of low intensity on T1-weighted images. T2-weighted images demonstrated mixed signal intensity. The range of area and degree of high signal intensity were different in each case. Post-contrast T1-weighted images with/without fat suppression revealed inhomogeneous enhancement of the lesion.

A typical desmoid tumor exhibits iso-intensity on T1-weighted images, high intensity on T2-weighted images, and marked heterogeneous enhancement on enhanced T1-weighted images (12-14). Although slight differentiation in results from T2-weighted images may be observed, it is difficult to distinguish collagenous fibroma from desmoid tumors. These decreased signal areas on T1- and T2- weighted images probably reflect the abundant collagen content $(12,15,16)$. These results are a common characteristic for tumors with fibrous components. The low intensity areas correspond to areas of dense collagen, while the high intensity areas may represent areas of increased cellularity or fibromyxoid matrices within the tumor (10). Therefore, it is unlikely that collagenous fibroma may be distinguished from desmoid tumors based on MRI analysis alone.

The usefulness of PET scans for the differentiation between soft tissue sarcomas and benign lesions is well known. However, aggressive tumors, including desmoid tumors, often exhibit results similar to sarcoma (14,17-22). Certain studies have included data from PET scans of desmoid tumors (14,17-19). In a study by $\mathrm{Xu}$ et al (14), the median value of $\mathrm{SUV}_{\max }$ on PET scans was 3.1 (range, 2.0-7.3), and Kasper et al (18) described a median $\mathrm{SUV}_{\max }$ value 4.1 (range, 1.0-8.1). In addition, Xu et al (14) suggested that desmoid tumors usually appear moderately hypermetabolic on PET scans even in large masses, while smaller tumors tend to appear hypometabolic. To the best of our knowledge, the present case report is the first description of the appearance of collagenous fibroma on PET scans. In the present study, uptake by the tumor in the subacromial region was relatively low compared with desmoid tumors $(14,18)$. As aforementioned, this tumor exhibited a pattern on the MRI scans similar to desmoid tumors, but low cellularity and rare or absent mitosis on histological examination. This feature may affect the aggressiveness of the tumor, similar to previous case reports of desmoid tumors (19-21).

Thallium-201 scintigraphy also is useful to differentiate between soft tissue sarcomas and benign lesions. Relatively aggressive tumors, including giant cell tumors of the tendon sheath, pigmented villonodular synovitis, neurofibroma and desmoid 

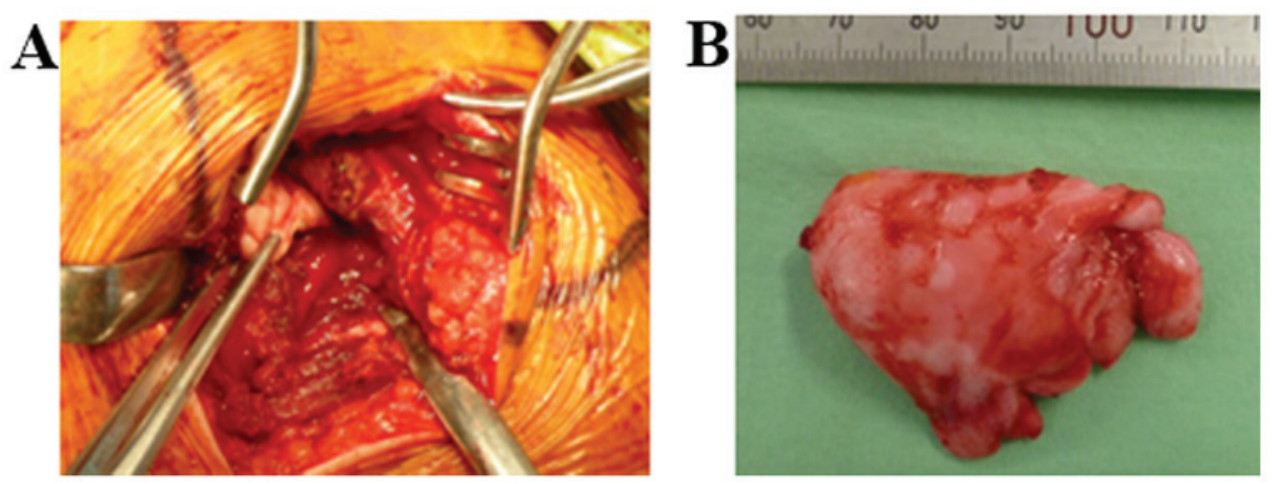

Figure 5. Intraoperative results and macroscopic examinations. (A) During surgery, a white mass that was pinched by forceps was identified in the subacromial space following splitting of the deltoid muscle. (B) Macroscopically, the tumor was a white, elastic, hard and well-circumscribed mass.
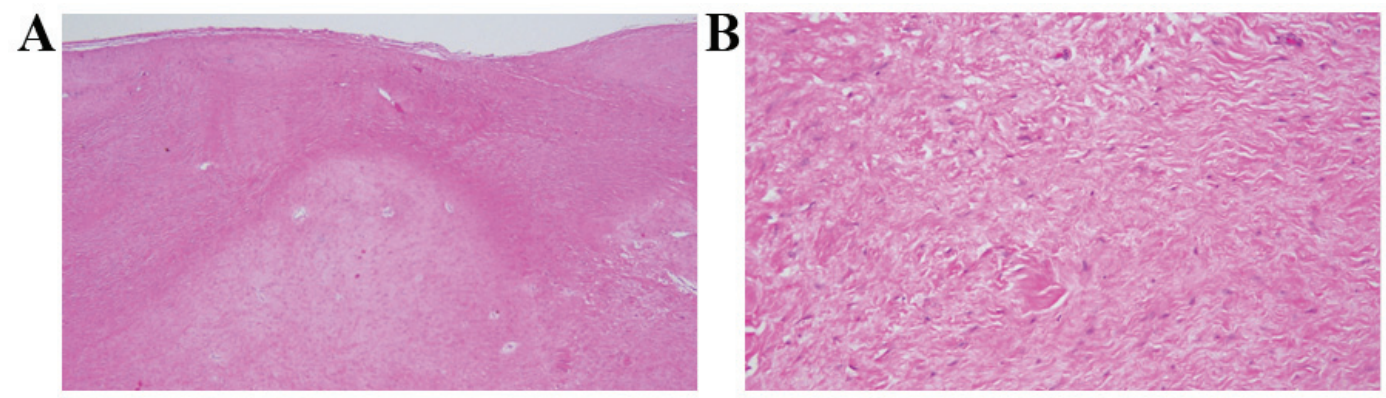

Figure 6. Microscopic examination using hematoxylin and eosin staining. (A) The tumor demonstrated fibrous and myxomatous matrix areas. Few vascular spaces were observed (magnification, x40). (B) Spindle- or stellate-shaped cells with oval nuclei were present in the dense collagenous matrix (magnification, $\mathrm{x} 100)$.

tumor, demonstrate high uptake on thallium-201 scintigraphy, compared with the majority of other benign tumors (23-26). In the present case report, no accumulation of thallium-201 scintigraphy was observed in the area of the tumor, which poses the question of whether or not the tumor was present 1 year ago. However, this cannot be confirmed as MRI and PET scans were not performed at that time point, due to the lack of uptake of thallium-201 scintigraphy. However, it is difficult to conclusively state that this tumor, which was $>5 \mathrm{~cm}$, was absent 1 year ago, as growth of collagenous fibroma is not rapid. Therefore, using the results of the present study, thalium-201 scintigraphy may be able to differentiate desmoid tumors from collagenous fibroma, although the usefulness of thallium-201 scintigraphy in collagenous fibroma has not been previously described.

In conclusion, the present case study has described multimodal data, including MRI scans, thallium-201 scintigraphy and PET scans of a collagenous fibroma arising from the subacromial region. Regarding thallium-201 scintigraphy and PET scans, these are not gold standard imaging techniques for soft tissue tumors. As aforementioned, the majority of tumors, including desmoid tumors, exhibit similar results for PET scans and thallium-201 scintigraphy. However, the present case exhibited distinct results between PET scans and thallium-201 scintigraphy. Although the detailed mechanism is unclear, different results between PET scans and thallium-201 scintigraphy may be a characteristic of collagenous fibroma. The multimodal radiological data of this case may be useful as an additional tool to differentiate between collagenous fibroma and desmoid tumors for future investigations. Methods to correctly diagnose this tumor are important in order to select the appropriate management strategies, including surgical treatment.

\section{Acknowledgements}

Not applicable.

\section{Funding}

No funding was received.

\section{Availability of data and materials}

All data generated or analyzed during this study are included in this published article.

\section{Authors' contribution}

HM designed the study, contributed to analysis of data, and wrote the manuscript. All authors, including KI, KN and YN, have contributed to the clinical management of the patient. All authors critically reviewed the manuscript and approved the final manuscript.

\section{Ethics approval and consent to participate}

Ethical approval for this study was obtained from Matsushita Memorial Hospital Ethics Committee (approval no. 18008). Written informed consent was obtained from the patient. 


\section{Patient consent for publication}

Written informed consent was obtained from the patient.

\section{Competing interests}

The authors declare that they have no competing interests.

\section{References}

1. Evans HL: Desmoplastic fibroblastoma. A report of seven cases. Am J Surg Pathol 19: 1077-1081, 1995.

2. Nielsen GP, O'Connell JX, Dickersin GR and Rosenberg AE: Collagenous fibroma (desmoplastic fibroblastoma): A report of seven cases. Mod Pathol 9: 781-785, 1996.

3. Miettinen M and Fetsch JF: Collagenous fibroma (desmoplastic fibroblastoma): A clinicopathologic analysis of 63 cases of a distinctive soft tissue lesion with stellate-shaped fibroblasts. Hum Pathol 29: 676-682, 1998.

4. Yamamoto A, Abe S, Imamura T, Takada K, Enomoto Y, Harasawa A, Matsushita $\mathrm{T}$ and Furui S: Three cases of collagenous fibroma with rim enhancement on postcontrast T1-weighted images with fat suppression. Skeletal Radiol 42: 141-146, 2013.

5. Walker KR, Bui-Mansfield LT, Gering SA and Ranlett RD Collagenous fibroma (desmoplastic fibroblastoma) of the shoulder. AJR Am J Roentgenol 183: 1766, 2004.

6. Marinelli M, Lupetti E, Gigante A, Mandolesi A, Bearzi I and de Palma L: Collagenous fibroma of the deltoid muscle: Clinical, surgical and histopathological aspects. J Orthop Traumatol 8: 91-94, 2007.

7. Bonardi M, Zaffarana VG and Precerutti M: US and MRI appearance of a collagenous fibroma (desmoplastic fibroblastoma) of the shoulder. J Ultrasound 17: 53-56, 2013.

8. Milnes LK, Tennent TD and Pearse EO: An unusual cause of subacromial impingement: A collagenous fibroma in the bursa J Shoulder Elbow Surg 19: e15-e17, 2010

9. Kamata Y, Anazawa U, Morioka H, Morii T, Miura K, Mukai M, Yabe $\mathrm{H}$ and Toyama $\mathrm{Y}$ : Natural evolution of desmoplastic fibroblastoma on magnetic resonance imaging: A case report. J Med Case Reports 5: 139, 2011.

10. Shuto R, Kiyosue H, Hori Y, Miyake H, Kawano K and Mori H: CT and MR imaging of desmoplastic fibroblastoma. Eur Radiol 12: 2474-2476, 2002.

11. Beggs I, Salter DS and Dorfman HD: Synovial desmoplastic fibroblastoma of hip joint with bone erosion. Skeletal Radiol 28: 402-406, 1999.

12. Ogose A, Hotta T, Emura I, Higuchi T, Kusano N and Saito H: Collagenous fibroma of the arm: A report of two cases. Skeletal Radiol 29: 417-420, 2000.
13. Hartman TE, Berquist TH and Fetsch JF: MR imaging of extraabdominal desmoids: Differentiation from other neoplasms. AJR Am J Roentgenol 158: 581-585, 1992.

14. Xu H, Koo HJ, Lim S, Lee JW, Lee HN, Kim DK, Song JS and Kim MY: Desmoid-type fibromatosis of the thorax: CT, MRI, and FDG PET characteristics in a large series from a tertiary referral center. Medicine (Baltimore) 94: e1547, 2015.

15. Sundaram M, McGuire MH and Schajowicz F: Soft-tissue masses Histologic basis for decreased signal (short T2) on T2-weighted MR images. AJR Am J Roentgenol 148: 1247-1250, 1987.

16. Kransdorf MJ, Jelinek JS, Moser RP Jr, Utz JA, Hudson TM, Neal J and Berrey BH: Magnetic resonance appearance of fibromatosis. A report of 14 cases and review of the literature. Skeletal Radiol 19: 495-499, 1990.

17. Souza FF, Fennessy FM, Yang Q and van den Abbeele AD: Case report. PET/CT appearance of desmoid tumour of the chest wall. Br J Radiol 83: e39-e42, 2010.

18. Kasper B, Dimitrakopoulou-Strauss A, Strauss LG and Hohenberger P: Positron emission tomography in patients with aggressive fibromatosis/desmoid tumours undergoing therapy with imatinib. Eur J Nucl Med Mol Imaging 37: 1876-1882, 2010.

19. Nishio J, Aoki M, Nabeshima K, Iwasaki H and Naito M: Imaging features of desmoid-type fibromatosis in the teres major muscle. In Vivo 27: 555-559, 2013.

20. Hourani R, Taslakian B, Shabb NS, Nassar L, Hourani MH, Moukarbel R, Sabri A and Rizk T: Fibroblastic and myofibroblastic tumors of the head and neck: Comprehensive imaging-based review with pathologic correlation. Eur J Radiol 84: 250-260, 2014.

21. Ebrahim L, Parry J and Taylor DB: Fibromatosis of the breast: A pictorial review of the imaging and histopathology findings. Clin Radiol 69: 1077-1083, 2014

22. Janssen ML, van Broekhoven DL, Cates JM, Bramer WM, Nuyttens JJ, Gronchi A, Salas S, Bonvalot S, Grünhagen DJ and Verhoef C: Meta-analysis of the influence of surgical margin and adjuvant radiotherapy on local recurrence after resection of sporadic desmoid-type fibromatosis. Br J Surg 104: 347-357, 2017.

23. Terui S, Terauchi T, Abe H, Fukuma H, Beppu Y, Chuman K and Yokoyama R: On clinical usefulness of Tl-201 scintigraphy for the management of malignant soft tissue tumors. Ann Nucl Med 8: 55-64, 1994.

24. Sato O, Kawai A, Ozaki T, Kunisada T, Danura T and Inoue H: Value of thallium-201 scintigraphy in bone and soft tissue tumors. J Orthop Sci 3: 297-303, 1998.

25. Murata H, Kusuzaki K, Hirata M, Hashiguchi S and Hirasawa Y: Extraabdominal desmoid tumor with dissemination detected by thallium-201 scintigraphy. Anticancer Res 20: 3963-3966, 2000.

26. Kawakami N, Kunisada T, Sato S, Morimoto Y, Tanaka M, Sasaki T, Sugihara S, Yanai H, Kanazawa S and Ozaki T: Thallium-201 scintigraphy is an effective diagnostic modality to distinguish malignant from benign soft-tissue tumors. Clin Nucl Med 36: 982-986, 2011. 